\title{
Progression of irregular opacities in asbestos miners
}

\author{
G K SLUIS-CREMER, EVA HNIZDO \\ From the Epidemiology Research Unit, Medical Bureau for Occupational Diseases, PO Box 4584, Johannesburg \\ 2000, Republic of South Africa
}

\begin{abstract}
All white and mixed race men who were employed in South African asbestos mines and $\vec{\circ}$ mills between 30 November 1970 and 30 November 1975 were studied. The men who had two radiographs available, the first taken some time between the above two dates and the latest available $\omega$ radiograph which had to be at least two years after the first one numbered 1454: 793 continued exposure after the first radiograph and 661 did not. The films were read by a panel of three readers. Data available included age, years of exposure to asbestos and other mining, intensity of exposure to of asbestos and other dust, and smoking habit. Progression was expressed as the difference between the $\overrightarrow{\mathrm{N}}$ average readings of radiograph 2-radiograph 1 in minor categories per year of irregular opacities. Changes in pleural abnormality were also measured. No differences of progression in the profusion or $\vec{b}$

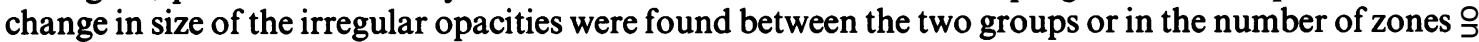
affected. "New attacks" appeared equally frequently between the two groups. No difference in the change in extent of any type of pleural change was seen. It appears that once a dose of asbestos sufficient to initiate the disease has been retained it is inexorably progressive.
\end{abstract}

The effect of removal from exposure to asbestos dust on progression of radiological change has been studied by several authors working on relatively small groups of exposed men who have usually been exposed to chrysotile or chrysotile with a small admixture of amphibole. ${ }^{1-9}$ In one study the exposure was purely to Western Australian crocidolite. ${ }^{10}$

The present study was performed on men whose predominant exposure was to South African amphibole (crocidolite and amosite) asbestos. The objectives were:

(1) to determine if the progression of irregular opacities was slowed down or stopped or reversed after exposure to asbestos ceased, particularly in the case of low profusion of irregular opacities; and

(2) to determine whether irregular opacities appeared de novo after exposure ceased and if so how commonly.

\section{Methods}

\section{STUDY SUBJECTS}

All 2185 white and mixed race men employed by asbestos mines and mills on 30 November 1970 or who had entered employment (often by re-employment) up to 30 November 1975 were studied in a radiological cross sectional study." The men from the cross sectional study were chosen for this study if they had $\vec{\varphi}$ had a follow up radiograph taken at least two yeaf 0 after the radiograph used for the cross sectional stud The maximum follow up time was up to mid-198 Workers with missing exposure data or no follow up radiograph were excluded. The group remaining for the progressicn study amounted to 1454 men. Of these, 793 had exposure after the first radiograph and 661 did not. Eighty five men had exposure to chrysotile only.

\section{RADIOLOGICAL READINGS}

A panel of three experienced radiograph readers read the films using the full 1980 ILO classification of $\frac{\Phi}{3}$ Radiographs of the Pneumoconioses, the standard 0 films and the side by side reading method. The films 3 . were marked to indicate the chronological order, the of film used in the original cross sectional study (marked 1) and the latest available film (marked 2), but the $ᄋ$ dates of the films were covered so that the readers were $\rightarrow$ blinded as to the duration of the period between the two films. The readers had no other information except that they knew the men had been exposed to $\sigma$ asbestos. Nearly all the films were $35 \times 43 \mathrm{~cm}$. In N some cases only $100 \mathrm{~mm}$ films were available for the $\mathrm{N}$ dates required and then these were read. Only $\underset{\sigma}{\sigma}$ posteroanterior views were read.

The profusion of irregular opacities was read in $\stackrel{0}{=}$ minor categories and recorded so that each minor 
category was assigned a value between 0 and 10 -that is, $0 / 0$ became $0,0 / 1$ became 1 , and, finally, $3 / 4$ became 10 ( $0 /$ - was not used). The distribution of the opacities was graded by a score of one to six according to the number of zones affected. The size of the irregular opacities was graded with a numerical score from 0 to 3 as follows ss $=1$, st/ts $=2, u t / t u / t t=3$. The score for pleural change was expressed as an area, calculated as extent times width where width was measurable. Width in terms of $\mathrm{a}, \mathrm{b}, \mathrm{c}$ was transformed into $1,2,3$. For en face plaques, width was assumed to be one and the area therefore was the same as the extent. All pleural changes in right and left hemithoraces were then summed. No distinction was made between plaques and diffuse pleural thickening.

\section{MINING EXPOSURES}

Mining exposures to asbestos, gold, and other mining (for copper, tin, or antimony, for example) were coded in terms of years of exposure and also in terms of fibreyears in the case of asbestos. Years of exposure were calculated from shifts worked ( 280 shifts $=1$ year). Fibre-years were computed by summing over all the occupations the man had worked in asbestos mines and the years spent in a particular occupation weighted by the estimated fibre level for that occupation at that particular mine at the relevant time. Fibre levels were available since 1945 for individual asbestos mines at different calendar periods and for different occupations. The groups are characterised by relatively short service, on average under conditions of moderately intense fibre exposure. A threshold limit value of 2 fibres/cc was imposed in 1984 only shortly before the termination of this project. It should be noted that the fibre exposures have been continuously computed for the subjects in this study since 1970 and updated every six months. In the earlier period if the total exposure of the man who left the mine amounted to less than 500 fibre-shifts the exposure was recorded as zero. Fibreyears worked before November 1970 were computed using information given by the man himself as to the mine he had worked at and the job he had held for different calendar periods. Asbestos, gold, and other mining exposures were calculated for two periods. The first period was from the start of mining exposure to the date of the first radiograph and the second was the period between the two radiographs.

\section{SMOKING HABIT}

Smoking habits were established at the time of first radiograph and categorised as never smoker $(18.5 \%)$, current smoker 1-10 cigarettes/day $(21.9 \%)$, exsmoker $>2$ years $(3.4 \%)$, current smoker $>11$ cigarettes/day ( $54.3 \%)$, unknown (1.9\%). Cigars and pipe tobacco were converted to cigarettes as follows; small cigar 2, large cigar 5 , ounce of tobacco 28 . The subjects with the unknown smoking values were excluded from the analysis in which smoking was considered.

\section{STATISTICAL ANALYSIS}

Three progression variables were calculated for the profusion of irregular opacities over the three readers:

(a) average progression rate/y (APRIO)

$$
\text { ARPIO }=1 / 3 \sum_{i=1}^{3}\left(\text { reading } 2_{i}-\text { reading } 1_{i}\right) / \text { time }(y)
$$

(b) average progression (APIO)

$$
\text { APIO } \left.=1 / 3 \sum_{i=1}^{3} \text { (reading } 2_{i}-\text { reading } 1_{i}\right)
$$

(c) progression (yes/no) by one or more major category (PIO).

The average major category or profusion was calculated by averaging the profusion score over the three readers and then the categories were defined as follows: category $0 / 0$ was assigned to average profusion score of $<0.5,0 / 1$ to score $0.5-<1.5,1 / 0-1 /$ 2 to score $1 \cdot 5-<4.5,2 / 1-2 / 3$ to score $4.5-<7 \cdot 5$, and $>2 / 3$ to score $>7 \cdot 5$. Then PIO was assigned the value 1 if the average category of profusion changed by one or more, major categories and 0 otherwise.

The relation between the variables $(a)$ and $(b)$ and exposure to asbestos was estimated by means of a stepwise multivariate linear regression analysis (SAS package, PROC STEPWISE and PROC REG). The potential confounding effects of smoking (SMOKE), gold mining and other mining exposure, age at first radiograph (AGE), the average initial reading for irregular opacities (AIO1), years of follow up (YFUP), and year of birth were considered in the analysis. The standardised means were calculated with analysis of covariance (SAS package, PROC GLM). The logistic regression model (PROC LOGIST) was applied for the analysis of variable $(c)$-that is, progression yes/ no, using the same potential confounding variables as for the linear regression analysis. The central limit theorem which states that whenever " $n$ " is moderately large then the mean is approximately normally distributed regardless of the distribution of the underlying variable was applied when comparing the two groups.

\section{Results}

\section{COMPARISON OF THE EXPOSED AND UNEXPOSED} MINERS

Table 1 describes the study population. There were 793 men who had been exposed after the first radiograph and 661 who had not. The two groups differed significantly in their history of exposure to asbestos mining up to the time of the first radiograph, the years 
Table 1 Comparison between miners exposed and miners not exposed to asbestos mining after the first radiological examination for exposure characteristics

\begin{tabular}{|c|c|c|c|c|c|}
\hline \multirow[b]{3}{*}{ Characteristic } & \multicolumn{5}{|c|}{ Exposure after first radiograph } \\
\hline & \multicolumn{2}{|c|}{ Yes $(n=793)$} & \multicolumn{2}{|c|}{ No $(n=661)$} & \multirow[b]{2}{*}{$p$} \\
\hline & Mean & $S D$ & Mean & $S D$ & \\
\hline $\begin{array}{l}\text { Year of birth } \\
\text { Age at 1st radiograph } \\
\text { Year of 1st radiograph } \\
\text { Year of 2nd radiograph } \\
\text { Year of follow up }\end{array}$ & $\begin{array}{r}37 \cdot 7 \\
36 \cdot 4 \\
74 \cdot 1 \\
82 \cdot 1 \\
8 \cdot 0\end{array}$ & $\begin{array}{r}10 \cdot 7 \\
10 \cdot 9 \\
1 \cdot 2 \\
3 \cdot 4 \\
3 \cdot 4\end{array}$ & $\begin{array}{r}37 \cdot 6 \\
35 \cdot 2 \\
72 \cdot 8 \\
81 \cdot 5 \\
8 \cdot 7\end{array}$ & $\begin{array}{r}10 \cdot 8 \\
10 \cdot 9 \\
1.5 \\
3.7 \\
3.8\end{array}$ & $\begin{array}{l}0.82 \\
0 \cdot 04 \\
0 \cdot 0001 \\
0 \cdot 002 \\
0 \cdot 0001\end{array}$ \\
\hline $\begin{array}{l}\text { Mining exposure to lst r } \\
\text { Asbestos (y) } \\
\text { Asbestos (f/y) } \\
\text { Gold (y) } \\
\text { Other (y) }\end{array}$ & $\begin{array}{c}\text { adiograp } \\
6 \cdot 7 \\
38 \cdot 4 \\
2 \cdot 0 \\
1 \cdot 1\end{array}$ & $\begin{array}{r}\text { he } \\
6 \cdot 5 \\
73 \cdot 1 \\
4 \cdot 8 \\
3 \cdot 2\end{array}$ & $\begin{array}{r}4 \cdot 2 \\
23 \cdot 2 \\
3 \cdot 1 \\
1 \cdot 3\end{array}$ & $\begin{array}{r}5 \cdot 5 \\
61 \cdot 4 \\
5 \cdot 7 \\
3 \cdot 1\end{array}$ & $\begin{array}{l}0.0001 \\
0.0001 \\
0 \cdot 0001 \\
0.40\end{array}$ \\
\hline $\begin{array}{l}\text { Between 1st and 2nd rad } \\
\text { Asbestos (y) } \\
\text { Asbestos (f/y) } \\
\text { Gold (y) } \\
\text { Other (y) }\end{array}$ & $\begin{array}{l}\text { ograph: } \\
4 \cdot 5 \\
6 \cdot 2 \\
0 \cdot 3 \\
0 \cdot 6\end{array}$ & $\begin{array}{l}3 \cdot 3 \\
9 \cdot 8 \\
1 \cdot 1 \\
1 \cdot 6\end{array}$ & $\begin{array}{l}1.0 \\
1.8\end{array}$ & $\begin{array}{l}2 \cdot 4 \\
3 \cdot 3\end{array}$ & $\begin{array}{l}0.0001 \\
0.0001\end{array}$ \\
\hline $\begin{array}{l}\text { Smoking category: } \\
\text { Never smoked } \\
1-10 \text { cig/day } \\
\text { Ex-smoker } \\
\text { ₹ } 11 \text { cig/day } \\
\text { Unknown }\end{array}$ & $\begin{array}{r}N o \\
148 \\
176 \\
29 \\
424 \\
16\end{array}$ & \begin{aligned} \multicolumn{1}{c}{$\%$} \\
$18 \cdot 7 \\
22 \cdot 2 \\
3 \cdot 7 \\
53 \cdot 5 \\
2 \cdot 0\end{aligned}$ & $\begin{array}{r}N o \\
121 \\
143 \\
20 \\
365 \\
12\end{array}$ & \begin{aligned} \multicolumn{1}{l}{$\%$} \\
$18 \cdot 3 \\
21 \cdot 6 \\
3 \cdot 0 \\
55 \cdot 2 \\
1 \cdot 8\end{aligned}$ & \\
\hline
\end{tabular}

of exposure were $6.7(\mathrm{SD}, 6.5)$ and $4.2(\mathrm{SD}, 5.5)$ and fibre-years were 38.4 (SD 73.1) and 23.2 (SD 61.4) for those exposed and not exposed after first radiograph, respectively. Several other characteristics showed statistically significant differences between the two groups (see table 1), but the differences were not considered important for this study. Smoking categories were virtually identical in the two groups. The mean years of follow up were similar for the exposed and the unexposed groups, 8.0 (SD, 3.4) and 8.7 (SD, 3.8) years respectively. The maximum follow up was 16.5 years.

\section{COMPARISON OF THE RADIOGRAPH READERS}

Table 2 compares the three readers for the number of cases in whom they considered progression of IO had taken place and for the degree of progression, expressed as major categories. Reader 2 read progression more frequently and to a greater extent than the other two readers, and reader 1 read apparent regression more commonly. The differences between the readers were considered to be acceptable. Table 3 shows the proportions of agreement on whether progression was present or not among the three readers. Agreement was considered satisfactory, the proportion was over 0.7 in all cases. This reasonable agreement, however, was in some measure due to agreement that progression was absent and there were somewhat larger disagreements when readers thought there was progression; when reader 1 thought there was progres- sion (n 429) reader 2 agreed in $282(66.7 \%$ ) and reader 3 agreed in 277 of $436(63.5 \%)$. When reader 2 thought there was progression reader 3 agreed only in $53 \cdot 4 \%$.

\section{AVERAGE PROGRESSION RATE/YEAR OF IRREGULAR OPACITIES}

Table 4 gives the factors found to be significantly related to the average progression rate of irregular opacities a year (APRIO). The 28 subjects with missing smoking data were excluded from this analysis. The results are presented for all the subjects and then separately for those exposed after the first radiograph and for those not so exposed. Age at first radiograph, average profusion of irregular opacities at first radiograph, smoking category, and years of exposure to asbestos to first radiograph were found to be significant predictors for both groups. The estimated regression coefficients did not statistically differ for the two groups as no significant interaction between any of them and the group $(0,1)$ variable was observed. It should be noted, however, that for the group not exposed after the first radiograph the average profusion at first radiograph was the most important predictor. Asbestos exposure after the first radiograph was a significant factor for those who continued exposure only in terms of fibre-years. Years of exposure in gold mines was not significantly related to progression rate and the exposure to other mining was of marginal significance in both the exposed and unexposed group.

\section{AVERAGE PROGRESSION OF PROFUSION}

The variables found to be significantly related to the average progression of profusion (APIO) were AGE, years of asbestos mining exposure to first radiograph (YAEXP1), YFUP, AI01, and SMOKE. The presence of asbestos exposure after the first radiograph was not found to be statistically significant. Table 5 shows the effect of years of follow up on APIO. The means for APIO were standardised for the effect of the other variables. The miners with 12 or more years of follow up had the highest value for progression. Even though the miners with the longest follow up were on average

Table 2 Progression by minor categories for three readers

Progression (No of categories)

\begin{tabular}{llcccccc}
\hline Reader & & $<0^{*}$ & 0 & 1 & 2 & $>3$ & Total \\
\hline 1 & No & 43 & 972 & 180 & 137 & 122 & 1454 \\
& $\%$ & 3.0 & 66.9 & 12.4 & 9.4 & 8.4 & $100 \cdot 1$ \\
2 & No & 22 & 859 & 239 & 138 & 169 & $1427 \dagger$ \\
& $\%$ & 1.5 & 60.2 & 16.8 & $9 \cdot 7$ & 11.8 & $100 \cdot 0$ \\
3 & No & 13 & 988 & 211 & 133 & 102 & $1447 \dagger$ \\
& $\%$ & 0.9 & 68.3 & 14.6 & $9 \cdot 2$ & $7 \cdot 1$ & $100 \cdot 1$ \\
\hline
\end{tabular}

* 0 indicates apparent regression.

†Reader 2 rejected 27 films as unreadable, reader 3 rejected seven. 
Table 3 Agreement on progression between the three readers

\begin{tabular}{|c|c|c|c|c|}
\hline & Progressed & Yes & No & Total \\
\hline \multicolumn{5}{|c|}{ Reader 2} \\
\hline Reader 1 & $\begin{array}{l}\text { Yes } \\
\text { No } \\
\text { Total }\end{array}$ & $\begin{array}{l}282 \\
264 \\
546\end{array}$ & $\begin{array}{l}147 \\
734 \\
881\end{array}$ & $\begin{array}{c}429 \\
998 \\
1427^{*}\end{array}$ \\
\hline \multicolumn{5}{|c|}{ Proportion in agreement $=1016 / 1427=0.71$} \\
\hline Reader 1 & $\begin{array}{l}\text { Yes } \\
\text { No } \\
\text { Total } \\
\text { in agreemen }\end{array}$ & $\begin{array}{l}R e \\
277 \\
169 \\
446 \\
1119\end{array}$ & $\begin{array}{r}159 \\
842 \\
1001 \\
0.77\end{array}$ & $\begin{array}{c}436 \\
1011 \\
1447^{*}\end{array}$ \\
\hline Proportior & $\begin{array}{l}\text { Yes } \\
\text { No } \\
\text { Total } \\
\text { in agreemen }\end{array}$ & $\begin{array}{l}R e \\
290 \\
148 \\
438 \\
1019\end{array}$ & $\begin{array}{r}253 \\
729 \\
982 \\
0.72\end{array}$ & $\begin{array}{c}543 \\
877 \\
1420^{*}\end{array}$ \\
\hline
\end{tabular}

*Number of radiographs rejected as unreadable were 27 for reader 2 and seven for reader 3 .

younger, the highest progressors among them were men who were over 35 (of 202 men with more than 12 years follow up in 90 aged under 30 , irregular opacity change was $0 \cdot 31$, whereas in 65 aged $35-44$ it was $1 \cdot 78$ ). The table confirms that the two groups did not differ in their pattern of progression of irregular opacities with respect to AGE, YFUP, and AIO1. The APRIO is also given for comparison.

\section{PROGRESSION BY MAJOR CATEGORY}

OF PROFUSION IN IRREGULAR OPACITIES

Table 6 presents the mean radiological readings for irregular opacities in the second radiograph according to the readings in the first one for those who were and those who were not exposed after the first radiograph separately. A considerable amount of progression is evident in both groups, $80 / 648$ men whose initial reading was $0 / 0(12 \cdot 3 \%)$ in the exposed group and $58 /$ $549(10.6 \%)$ in the unexposed group progressed to a reading of $1 / 0$ or more - that is, new "attacks." The difference was not significant. Of those read $0 / 1$ in the first film, $53 / 88(60 \%)$ progressed in those with exposure after first radiograph and $46 / 69(67 \%)$ had so progressed in those without further exposure. The table does not indicate that the subjects exposed after the first radiograph progressed more than those not so exposed. The variables found to be significantly related to the presence of progression (PIO) were AGE, YAEXP1, YFUP, SMOKE, and AIO1 and again the two groups were not found to differ. In addition we also examined the factors related to progression $(a)$ from category $0 / 0$ to category $0 / 1,(b)$ from category $0 / 0$ to $>0 / 1$, and $(c)$ from category $>0 /$ 1 to any higher category. For group (a) only AGE and YFUP were found to be significant. For groups $(b)$ and $(c)$ all the four variables mentioned above were statistically significant, but a pattern emerged in the strength of the association. For group (c) AGE and SMOKE were higher predictors than for group $(b)$ and for group (b) YFUP was a stronger predictor.

\section{Discussion}

This is a relatively large radiological progression study on asbestos miners and millers with relatively few years of exposure and accumulated fibre-years (table 1); most of the subjects were exposed to amphibole. The reading of the films was by the side by side method to the full 1980 ILO classification. This choice was supported by most of those who have studied the problem of reading radiological progression in pneumoconioses and the relative merits of side by side and independent randomised reading. ${ }^{12-14}$ The readers

Table 4 Factors related to the progression rate/year of irregular opacities (IO), averaged over the three readers (APRIO)

\begin{tabular}{|c|c|c|c|c|}
\hline Variable & $\boldsymbol{\beta}$ & $S E$ & $R^{2}$ & $p$ \\
\hline \multicolumn{5}{|l|}{ (a) For all 1425 subjects } \\
\hline $\begin{array}{l}\text { Age at lst radiograph } \\
\text { AVIO profusion at } 1 \text { st radiograph } \\
\text { Smoking category } \\
\text { Asbestos exposure to 1st radiograph }(y)\end{array}$ & $\begin{array}{l}0.003 \\
0.050 \\
0.015 \\
0.004\end{array}$ & $\begin{array}{l}0.0004 \\
0.007 \\
0.003 \\
0.001\end{array}$ & $\begin{array}{l}0.12 \\
0.04 \\
0.01 \\
0.01\end{array}$ & $\begin{array}{l}0.0001 \\
0.0001 \\
0.0001 \\
0.0001\end{array}$ \\
\hline $\begin{array}{l}\text { (b) For } 777 \text { subjects exposed to asbestos after 1st radiograph } \\
\text { Age at 1st radiograph } \\
\text { Av } 10 \text { profusion at lst radiograph } \\
\text { Smoking category } \\
\text { Asbestos exposure to 1st radiograph (y) } \\
\text { Asbestos exposure after radiograph (f/y) } \\
\text { Other exposure (y) }\end{array}$ & $\begin{array}{r}0.003 \\
0.035 \\
0.017 \\
0.003 \\
0.016 \\
-0.003\end{array}$ & $\begin{array}{l}0.001 \\
0.009 \\
0.005 \\
0.001 \\
0.005 \\
0.002\end{array}$ & $\begin{array}{l}0.09 \\
0.02 \\
0.01 \\
0.01 \\
0.01 \\
0.003\end{array}$ & $\begin{array}{l}0.0001 \\
0.001 \\
0.001 \\
0.002 \\
0.003 \\
0.08\end{array}$ \\
\hline $\begin{array}{l}\text { (b) For } 648 \text { subjects not exposed to asbestos after 1st radiograph } \\
\text { Av } 10 \text { at lst radiograph } \\
\text { Age at 1st radiograph } \\
\text { Asbestos exposure to 1st radiograph (y) } \\
\text { Smoking category } \\
\text { Other exposure to 1st radiograph (y) }\end{array}$ & $\begin{array}{l}0.068 \\
0.003 \\
0.004 \\
0.013 \\
0.004\end{array}$ & $\begin{array}{l}0 \cdot 01 \\
0 \cdot 001 \\
0 \cdot 001 \\
0 \cdot 004 \\
0.002\end{array}$ & $\begin{array}{l}0.18 \\
0.06 \\
0.01 \\
0.01 \\
0.005\end{array}$ & $\begin{array}{l}0.0001 \\
0.0001 \\
0.0001 \\
0.004 \\
0.04\end{array}$ \\
\hline
\end{tabular}

In five cases two readers considered a film unreadable. These were omitted from the analyses. Those with missing smoking data were also omitted from these analyses. 
Table 5 Change in profusion of irregular opacities (IO) adjusted for other effects

\begin{tabular}{|c|c|c|c|c|c|c|c|}
\hline \multirow[b]{2}{*}{$\begin{array}{l}\text { Years of } \\
\text { follow up }\end{array}$} & \multirow[b]{2}{*}{ No } & \multirow[b]{2}{*}{$\begin{array}{l}\text { Age at lst } \\
\text { radiograph }\end{array}$} & \multirow[b]{2}{*}{$\begin{array}{l}\text { Exposure to 1st } \\
\text { radiograph }(y)\end{array}$} & \multirow{2}{*}{$\begin{array}{l}\text { Exposed } \\
\text { Exposure from lst-2nd } \\
\text { radiograph }(f / y)\end{array}$} & \multirow[b]{2}{*}{$\begin{array}{l}\text { AVIO at } 1 s t \\
\text { radiograph }\end{array}$} & \multicolumn{2}{|c|}{$\begin{array}{l}\text { Change in } 10 \text { from } 2 \text { nd } \\
\text { radiograph }\end{array}$} \\
\hline & & & & & & $\overline{A P I O}$ & APRIo \\
\hline $\begin{array}{l}<3 \\
3-5 \\
5-7 \\
7-9 \\
9-12 \\
\geqslant 12\end{array}$ & $\begin{array}{r}86 \\
110 \\
114 \\
72 \\
308 \\
65 \\
755\end{array}$ & $\begin{array}{l}36 \cdot 1 \\
36 \cdot 1 \\
36 \cdot 1 \\
39.5 \\
36.9 \\
31.9\end{array}$ & $\begin{array}{l}4.9 \\
6 \cdot 4 \\
7 \cdot 2 \\
8 \cdot 1 \\
7 \cdot 3 \\
3.9\end{array}$ & $\begin{array}{l}3.6 \\
4.7 \\
5.5 \\
4.6 \\
7.9 \\
7.6\end{array}$ & $\begin{array}{l}0.22 \\
0 \cdot 29 \\
0 \cdot 30 \\
0 \cdot 26 \\
0 \cdot 28 \\
0 \cdot 12\end{array}$ & $\begin{array}{l}0.36 \\
0.46 \\
0.60 \\
0.97 \\
0.77 \\
0.96\end{array}$ & $\begin{array}{l}0.14 \\
0.11 \\
0.10 \\
0 \cdot 11 \\
0.07 \\
0.09\end{array}$ \\
\hline \multirow[b]{2}{*}{$\begin{array}{l}\text { Years of } \\
\text { follow up }\end{array}$} & & \multicolumn{4}{|c|}{ Not exposed } & \multicolumn{2}{|c|}{$\begin{array}{l}\text { Change in } 10 \text { from } 1 s t- \\
\text { 2nd radiograph }\end{array}$} \\
\hline & No & $\begin{array}{l}\text { Age at } 1 s t \\
\text { radiograph }\end{array}$ & $\begin{array}{l}\text { Exposure to 1st } \\
\text { radiograph }(y)\end{array}$ & $\begin{array}{l}\text { Exposure from lst-2nd } \\
\text { radiograph }(f \mid y)\end{array}$ & $\begin{array}{l}\text { AVIO at lst } \\
\text { radiograph }\end{array}$ & APIO & APRIo \\
\hline $\begin{array}{l}<3 \\
3-5 \\
5-7 \\
7-9 \\
9-12 \\
\geqslant 12\end{array}$ & $\begin{array}{r}66 \\
82 \\
73 \\
71 \\
208 \\
137 \\
637\end{array}$ & $\begin{array}{l}36.7 \\
34.0 \\
37.2 \\
37.4 \\
35.5 \\
32.9\end{array}$ & $\begin{array}{l}4.2 \\
3.4 \\
5.5 \\
5.7 \\
3.9 \\
3.6\end{array}$ & $\begin{array}{l}0.0 \\
0.0 \\
0.0 \\
0.0 \\
0.0 \\
0.0\end{array}$ & $\begin{array}{l}0.23 \\
0.13 \\
0.39 \\
0.45 \\
0.25 \\
0.15\end{array}$ & $\begin{array}{l}0.29 \\
0.48 \\
0.54 \\
0.77 \\
0.78 \\
1.00\end{array}$ & $\begin{array}{l}0 \cdot 12 \\
0 \cdot 11 \\
0 \cdot 10 \\
0 \cdot 10 \\
0.08 \\
0.08\end{array}$ \\
\hline
\end{tabular}

AVIO = Average profusion of irregular opacities, APIO $=$ average progression, APRIo $=$ average progression rate/y.

Table 6 Distribution of the mean radiological readings for irregular opacities (IO) on second radiograph according to the initial reading and according to the presence of asbestos exposure after the first radiograph

\begin{tabular}{|c|c|c|c|c|c|c|c|c|}
\hline \multirow[b]{2}{*}{ First reading } & \multicolumn{8}{|c|}{ Second reading } \\
\hline & $0 / 0$ & $0 / 1$ & $1 / 0-1 / 2$ & $2 / 1-2 / 3$ & $3 / 2-3 / 4$ & Total & $\%$ & 음 \\
\hline \multicolumn{9}{|c|}{ (a) Subjects exposed to asbestos after 1st radiograph } \\
\hline $\begin{array}{l}0 / 0 \\
0 / 1 \\
1 / 0-1 / 2 \\
2 / 1-2 / 3\end{array}$ & $\begin{array}{r}421 \\
3 \\
0 \\
0\end{array}$ & $\begin{array}{r}147 \\
32 \\
0 \\
0\end{array}$ & $\begin{array}{r}75 \\
48 \\
21 \\
1\end{array}$ & $\begin{array}{r}4 \\
4 \\
11 \\
2\end{array}$ & $\begin{array}{l}1 \\
1 \\
0 \\
0\end{array}$ & $\begin{array}{r}648 \\
88 \\
32 \\
3\end{array}$ & $\begin{array}{r}84 \cdot 1 \\
11 \cdot 4 \\
4 \cdot 2 \\
0 \cdot 4\end{array}$ & $\stackrel{乛}{?}$ \\
\hline $\begin{array}{l}\text { Total } \\
\%\end{array}$ & $\begin{array}{l}424 \\
55 \cdot 0\end{array}$ & $\begin{array}{c}179 \\
23 \cdot 2\end{array}$ & $\begin{array}{l}145 \\
18 \cdot 8\end{array}$ & 21 & $\begin{array}{l}2 \\
0 \cdot 3\end{array}$ & $\begin{array}{l}771 \\
100 \cdot 0\end{array}$ & $\begin{array}{l}100 \cdot 0 \\
100 \cdot 0\end{array}$ & \\
\hline \multicolumn{9}{|c|}{ (b) Subjects not exposed to asbestos after lst radiograph } \\
\hline $\begin{array}{l}0 / 0 \\
0 / 1 \\
1 / 0-1 / 2 \\
2 / 1-2 / 3\end{array}$ & $\begin{array}{r}377 \\
0 \\
0 \\
0\end{array}$ & $\begin{array}{r}114 \\
23 \\
0 \\
0\end{array}$ & $\begin{array}{r}50 \\
40 \\
18 \\
0\end{array}$ & $\begin{array}{l}8 \\
4 \\
8 \\
0\end{array}$ & $\begin{array}{l}0 \\
2 \\
4 \\
1\end{array}$ & $\begin{array}{r}549 \\
69 \\
30 \\
1\end{array}$ & $\begin{array}{r}84 \cdot 6 \\
10 \cdot 6 \\
4 \cdot 6 \\
0 \cdot 2\end{array}$ & \\
\hline $\begin{array}{l}\text { Total } \\
\%\end{array}$ & $\begin{array}{c}377 \\
58 \cdot 1\end{array}$ & $\begin{array}{l}137 \\
21 \cdot 1\end{array}$ & $\begin{array}{c}108 \\
16.6\end{array}$ & 20 & $\begin{array}{l}7 \\
1 \cdot 1\end{array}$ & $\begin{array}{l}649 \\
100 \cdot 0\end{array}$ & $100 \cdot 0$ & \\
\hline
\end{tabular}

were blinded as to the time lapse between two radiographs which varied from two to 16.5 years, knowledge of which might have influenced their readings.

Agreement among readers as to progression was probably as good as might be expected (tables 2 and 3 ) bearing in mind that progression was measured in minor categories and that few cases attained a profusion of category $2 / 1$ or higher (table 4 ). Observer variation both for profusion and progression may be expected to be at its greatest in the lower categories. The progression in profusion of irregular opacities was analysed as average progression rate/year (APRIO), average progression in profusion (APIO), and as progression by one or more average major category of profusion (PIO). The factors found to be related to all three variables were age at first radiograph, years of exposure to asbestos to first radiograph, average profusion of irregular opacities at first radiograph, tobacco smoking, and asbestos fibre-years after the second radiograph for the miners who continued exposure. No interaction effects were found to be statistically significant.

Age at first radiograph was found to be the strongest predictor of progression rate in the whole cohort and in the exposed group. The age effect was 
found to be much the same for the two groups $(b=$ $0.003, \mathrm{SE}=0.001$, table 4). The significant effect for age may be a true influence of age on progression (possibly due to immunological and endocrine changes with age). Nevertheless, in part at least one must consider the possibility that it is a reflection of nonspecific radiological change with age (due in particular to smoking). The interaction between AGE and SMOKE was more significant than the individual effect on its own but when AGE and SMOKE were included in the model it ceased to be significant, nevertheless indicating the association between age and smoking.

There is no consensus, however, on the effect of age on progression. Souranta et al in a small study with a follow up of only three to four years found progression to be greater in younger men. ${ }^{8}$ Liddell et al, however, found age at first radiograph to be a leading variable for the progression rate of irregular opacities. ${ }^{6}$ Cookson $e t a l$ in their study found age to have a weak effect ${ }^{10}$ as did Viallat et al. ${ }^{9}$ Becklake et al found no effect of age. $^{2}$

Smoking habit was clearly related to progression rate in this study in the total group and in the subgroups, and the effect was found for all three readers when analysed individually.

Viallat $e t a^{9}$ and Souranta $e t a^{8}$ found that nonprogressors smoked significantly less than progressors. Jones et al, ${ }^{5}$ Becklake et $a l^{2}{ }^{2}$ and Rubino et al failed to find an effect of smoking whereas Liddell et al actually found that smoking was protective. ${ }^{6}$ Our group has previously shown that smoking habit has an important effect on the reading of irregular opacities whereas smoking was not found to be associated with asbestosis at necropsy. ${ }^{15}$

Average reading of irregular opacity profusion on first radiograph was strongly related to progression rate in all groups, and for the group unexposed after the first radiograph the average profusion was found to be the most important predictor of progression rate, even more important than age. This result is consistent with the notion that asbestosis is an inexorably progressive disease in most cases once it has started. Liddell et al found in their study that irregular opacities on the first film was a major predictor of rate of progression of irregular opacities. ${ }^{6}$ Souranta et al also found that with increasing category of irregular opacities progression increased from their 1976-7 reading to $1979-81$ (in 85 patients). ${ }^{8}$

The years of exposure to asbestos to first radiograph was found to be a significant predictor of rate of progression for the combined and the individual groups. Fibre-years surprisingly was not significant once the years of exposure were entered into the regression model, except for the period between first and second radiographs in those who continued exposure. The reason why years of exposure is a far stronger factor than fibre-years may be because estimations of fibre concentrations in the earlier years (before the introduction of the membrane filter in the early 1970s) measured by the konimeter and thermal precipitator were not accurate enough. Cumulative asbestos exposure (fibre-years) was found to be significantly related to rate of progression in some studies $^{5910}$ but another study found little evidence of a relation. ${ }^{6}$

Years of follow up were significantly related to progression in profusion of irregular opacities (table 5) and to the presence of progression by one or more major categories of profusion. Table 5 also shows that the two groups did not differ in the progression pattern with respect to the years of follow up, age, and exposure to first radiograph.

It should be emphasised that the maximum follow up period after first radiograph was only 16.5 years but there were over 608 miners with more than 10 years of follow up. Becklake et al notes the importance of "lag time"" and Cookson et al state that many of their subjects would not have been considered as progressing at 20 years of follow up whereas they had progressed at 30 years. ${ }^{10}$ In our study 65 men with further exposure and 137 without who had more than 12 years of follow up had the same degree of change between the two radiographs and the same rate of progression. They were also virtually of the same average age and exposure up to the first radiograph and profusion reading on first radiograph (table 5).

The distribution of the mean radiological readings for irregular opacities on the second radiograph for the various initial readings (table 6) for the two groups separately show two features of interest. New attacks (readings of $1 / 0$ or higher on the second radiograph when the initial reading was $0 / 0$ ) were fairly common-that is, $80 / 648(12 \cdot 3 \%)$ for those with exposure after first radiograph and $58 / 549(10.6 \%)$ for those without such exposure. The difference is of no significance. A reading of $0 / 1$ had a serious prognosis in this study: $53 / 88(60 \%)$ progressed to a reading $1 / 0$ or greater in the exposed group and $46 / 69(66 \%)$ in the unexposed group.

The average change in the size of the irregular opacities with time was identical in the two groups. Two out of three readers found increases in $22.8 \%$ of the exposed and $22.4 \%$ of the unexposed. For increase in the number of zones affected the findings were $25.5 \%$ and $26.8 \%$ respectively. Costophrenic angle obliteration had appeared in $3.9 \%$ and $4.4 \%$, respectively, in the two groups. Pleural calcification had appeared or progressed in $2 \%$ of both groups. The calculated area of pleural change (see methods) had progressed in $13.8 \%$ and $14.8 \%$, respectively.

This study has found absolutely no differences in the evolution of radiological change between the group who continued exposure after the first radiograph and 
those who did not despite the fewer years of exposure and fewer fibre-years in the latter group up to the date of first radiograph. The same conclusion was reported from a study of workers exposed to asbestos. (nonminers) $)^{3}$ over a similar period of follow up as in this study.

There are some possible weaknesses in the study. A relatively short period of follow up means that the group who continued exposure had had only a mean of 4.5 years of exposure and 6.2 fibre-years after the first radiograph and that the time may have been too short for the additional exposure to take effect and the dose too low.

Cookson et al have shown how important duration of follow up is as progression in their study continued throughout 33 years and progression from category 0 to category 1 continued to happen throughout that period. ${ }^{10}$ Although their group was exposed to higher doses over a shorter period (median duration 37 months, median cumulative exposure 91 fibre-years), it is highly probable that new attacks and progression will continue to occur in the two groups in this study. Possibly with longer follow up the men who ceased exposure may be shown to have benefited.

To our knowledge, there are no published data to allow a comparison of radiological progression with time between chrysotile and amphibole exposed men. In the study of Liddell $e t$ al over a follow up period of 20 years in chrysotile miners the study group was selected in a different manner to this study. ${ }^{6}$ Nevertheless, his finding of new attacks of $12.5 \%$ to $16.2 \%$ is comparable with $12.3 \%$ and $10.6 \%$ in our exposed and unexposed groups, respectively. Unfortunately progression rate was calculated in different ways in the two studies and are not comparable.

Our results indicate that once a dose of asbestos sufficient to initiate the disease has been retained in the lungs the disease is inexorably progressive. The dose needed to initiate is no doubt influenced by many individual factors, genetic factors, differences in the rate of clearance of dust (which may, for instance, be affected by age and bronchial anatomy).

We are grateful for the work of the radiograph readers Dr F J Wiles and Dr R Glyn Thomas. The third reader was one of the authors (GKSC).
We also acknowledge the important contribution of all those concerned with the measuring and recording of dust concentrations in asbestos mines under the guidance of Dr R S J du Toit. Dr P A Hessel advised in the planning of this study.

\section{References}

1 Barnes R. Progression of radiographic changes in asbestos workers and ex-workers. J Soc Occup Med 1986;36:9-12.

2 Becklake MR, Liddell FDK, Manfreda J, McDonald JC Radiological changes after withdrawal from asbestos exposure. Br J Ind Med 1979;36:23-8.

3 Gaensler EA, Jederling PJ, McLoud PC. Progression of asbestosis. Poster session. Am Rev Respir Dis 1988;137:part 2, 92

4 Gregor A, Parkes RW, Du Bois R, Turner-Warwick M. Radiographic progression of asbestosis: preliminary report. Ann $N Y$ Acad Sci 1979;330:147-56.

5 Jones RN, Diem JE, Glindmeyer H, Weill H, Gilson JC. Progression of asbestos radiographic abnormalities: relationship to estimates of dust exposure and annual decline in lung function. In: Wagner JC, ed. Biological effects of mineral fibres. Vol 2. Lyon: International Agency for Research on Cancer, 537-40.(Sci publ No 30.)

6 Liddell D, Eyssen G, Thomas D, McDonald JC. Radiological changes over 20 years in relation to chrysotile exposure in Quebec. In: Walton WH, ed. Inhaled particles IV. Oxford: Pergamon Press, 1977:799-812.

7 Rubino GF, Newhouse M, Murray R, Scansetti G, Piolatto G, Aresini G. Radiological changes after cessation of exposure among chrysotile asbestos miners in Italy. Ann NY Acad Sci 1979;330:157-62.

8 Suoranta H, Huuskonen MS, Zitting A, Juntonen J. Radiographi progression of asbestosis. Am J Ind Med 1982;3:67-74.

9 Viallat JR, Boutin C, Pietri JF, Fondarai J. Late progression of radiographic changes in Canari chrysotile mine and mill ex workers. Arch Environ Health 1983;38:54-8.

10 Cookson W, De Klerk N, Musk AW, Glancy JJ, Armstrong B, Hobbs $M$. The natural history of asbestosis in former crocidolite workers of Wittenoom Gorge. Am Rev Respir Dis 1986;133:994-8.

11 Irwig LM, du Toit RSJ, Sluis-Cremer GK, et al. Risk of asbestosis in crocidolite and amosite mine in South Africa. Ann NY Acad Sci 1979;330:35-52.

12 Amandus HE, Reger BB, Pendergrass EP, Dennis JM, Morgan WKC. The pneumoconioses. Methods of measuring progression. Chest 1973;63:736-43.

13 Liddell FDK, Morgan WKC. Methods of assessing serial films of the pnemoconioses. A review. J Soc Occup Med 1978;28:6-15.

14 McMillan GHG, Rossiter CE, Deacon R. Comparison of independent randomised reading of radiographs with direct progression scoring for assessing change in pulmonary and pleural lesions. Br J Ind Med 1982;39:60-1.

15 Hnizdo E, Sluis-Cremer GK. Effect of tobacco smoking on the presence of asbestosis at post-mortem and on the reading of irregular opacities on roentgenograms in asbestos exposed workers. Am Rev Respir Dis 1988;138:1207-12. 